\title{
FORMAÇÃO PROFISSIONAL DO BIBLIOTECÁRIO
}

\author{
PROFESSIONAL EDUCATION OF LIBRARIANS
}

\author{
Maria Tereza Machado Teles Walter - terezaw@gmail.com \\ Doutoranda em Ciência da Informação, UnB \\ Membro do Grupo de Pesquisa Mercado de Trabalho do Profissional da Informação \\ Bibliotecária do Supremo Tribunal Federal \\ Sofia Galvão Baptista - sofiag@unb.br \\ Doutora em Ciência da Informação, UnB \\ Professora do Departamento de Ciência da Informação e Documentação, UnB \\ Líder do Grupo de Pesquisa Mercado de Trabalho do Profissional da Informação
}

\begin{abstract}
Resumo
A formação profissional de qualquer categoria profissional envolve aspectos variáveis que incluem questões sobre ética, empregabilidade, conceitos de trabalho, de profissão e de emprego. No caso específico dos bibliotecários, esses pontos são debatidos à luz da literatura, inserindo questões acerca do que seja a competência e de quais são aquelas mais ressaltadas pelos autores que tratam do tema, quando elaboram suas listas para evidenciar a necessidade de atenção dos profissionais que pretendem ser reconhecidos como modernos profissionais da informação. A tarefa de elaborar currículos que preencham todos os requisitos definidos é bastante complexa. Além disso, é inevitável a ênfase nas questões relacionadas às tecnologias de informação e de comunicação, cuja importância no trabalho dos bibliotecários é cada vez maior, seu uso mais intenso e determinante para aqueles que querem desenvolver produtos e serviços de informação cada vez mais adequados aos seus clientes.
\end{abstract}

Palavras-chave: Formação profissional do bibliotecário. Competência. Profissão. Emprego. Trabalho.

\section{INTRODUÇÃO}

Formação profissional é um tema amplo e envolve aspectos que compreendem desde a apreensão de conhecimentos específicos a fatores mais subjetivos que incluem ética profissional, empregabilidade e desenvolvimento da profissão. O enfoque do presente estudo é a discussão de alguns pontos que podem interferir nesse processo e na competitividade dos bibliotecários no mercado de trabalho.

Mais amplo que a formação profissional deste segmento específico, mas apresentando uma visão de integração em termos de cenário relacionada à questão de aquisição de conhecimentos, é o livro de Morin (2003) que delineia os "Os sete saberes necessários à educação do futuro" no qual ele identifica (p. 13-18) os "[...] problemas centrais ou fundamentais que permanecem totalmente ignorados ou esquecidos e que são necessários para se ensinar no próximo século." 
Na visão de Morin (2003) a relação ensino-aprendizagem não deve se limitar à aquisição de conhecimentos, mas também à formação de pessoas integradas socialmente com seu meio e com o mundo, capazes de responder às necessidades dos outros, aptas a perceber e se adaptar às mudanças e que sejam, sobretudo, éticas.

A formação dos bibliotecários, até pela natureza de algumas de suas atividades, de certo modo reponde a alguns dos pontos levantados, mas será que os currículos consideram todas essas questões? Será que ao pensar em um moderno profissional da informação pensa-se igualmente em um moderno ser humano nesse contexto globalizado?

Mesmo o autor reforçando que esses itens não são definitivos e que o desenvolvimento humano pode alterá-los, vale relacioná-los como fatores que devem permear os processos de transmissão e aquisição de conhecimento também para os bibliotecários. Os saberes necessários listados por Morin (2003, p. 13-18) constituem os capítulos específicos de seu livro e discutem:

- As cegueiras do conhecimento: o erro e a ilusão:

É impressionante que a educação que visa a transmitir conhecimentos seja cega ao que é o conhecimento humano, seus dispositivos, enfermidades, dificuldades, tendências ao erro e à ilusão, e não se preocupe em fazer conhecer o que é conhecer.

- Os princípios do conhecimento pertinente:

Existe um problema capital, sempre ignorado, que é o da necessidade de promover o conhecimento capaz de apreender problemas globais e fundamentais para neles inserir os conhecimentos parciais e locais.

- Ensinar a condição humana:

O ser humano é a um só tempo físico, biológico, psíquico, cultural, social, histórico. Esta unidade complexa da natureza humana é totalmente desintegrada na educação por meio das disciplinas, tendo-se tornado impossível apreender o que significa ser humano. É preciso restaurá-la, de modo que cada um, onde quer que se encontre, tome conhecimento e consciência, ao mesmo tempo, de sua identidade complexa e de sua identidade comum a todos os outros seres humanos.

- Ensinar a identidade terrena:

Será preciso indicar o complexo de crise planetária que marca o século $\mathrm{XX}$, mostrando que todos os seres humanos, confrontados de agora em diante aos mesmos problemas de vida e de morte, partilham um destino comum.

- Enfrentar as incertezas:

imprevistos, o inesperado e a incerteza, e modificar seu desenvolvimento, em virtude das informações adquiridas ao longo do tempo. É preciso aprender a navegar em um oceano de incertezas em meio a arquipélagos de certeza. Seria preciso ensinar princípios de estratégia que permitiriam enfrentar os.

- Ensinar a compreensão:

A compreensão é a um só tempo meio e fim da comunicação humana. Entretanto, a educação para a compreensão está ausente do ensino. O planeta necessita, em todos os sentidos, de compreensão mútua. Considerando a importância da educação para a compreensão, em todos os níveis educativos e em todas as idades, o desenvolvimento da compreensão pede a reforma das mentalidades. Esta deve ser obra da educação do futuro. 
- A ética do gênero humano:

A ética não poderia ser ensinada por meio de lições de moral. Deve formar-se nas mentes com base na consciência de que o humano é, ao mesmo tempo, indivíduo, parte da sociedade, parte da espécie. Carregamos em nós esta tripla realidade. Desse modo, todo desenvolvimento verdadeiramente humano deve compreender o desenvolvimento conjunto das autonomias individuais, das participações comunitárias e da consciência de pertencer à espécie humana.

Desse arcabouço bastante amplo, então, derivam-se questionamentos acerca do que deve constituir o elenco de conteúdos ministrados aos bibliotecários de tal forma que se constituam em um grupo profissional atuante, reconhecido socialmente, relevante para a sociedade e apto a desenvolver os caminhos da profissão. Assim como qualquer tema nas ciências, esse processo não é apenas um exercício filosófico, mas fundamentalmente uma visão de mundo e de prospecção para todas as profissões.

E, neste sentido, colocam-se questões anteriores acerca do que se entende por profissão, do que distingue emprego e trabalho e de que se constitui o constructo de competência profissional.

\section{PROFISSÃO}

Quando se falava em profissão, até meados do século $\mathrm{XX}$, não havia maiores dificuldades de identificação de fronteiras de atuação, jurisdições, competências e reconhecimento social de existência deste ou daquele grupo específico. Isto porque o elenco de profissões não era muito amplo, as práticas eram mais decisivas na formação das pessoas do que a academia e a idéia de profissionalização de algumas profissões é um fenômeno relativamente recente para muitas delas. Ressalve-se, inclusive, que no quesito relacionado com reconhecimento social não está embutida a forma pela qual a sociedade reconhece, mas apenas a constatação de que aquele grupo se distingue de outros e que a sociedade "conhece" isso.

No caso de definição de profissão, o trabalho de Mueller (2004) apresenta uma proposta de entendimento da concepção de profissão sob a ótica de Abbott, que identifica que as profissões existem num mesmo sistema e que competem por espaço e poder, que parecem ser os dois itens dominantes nessa visão. Embora extraído do texto da autora dessa maneira simplista, esse processo extremamente complexo de relações entre os diferentes profissionais implica em disputa do espaço de atuação, denominado de jurisdição, que é a "[...] relação entre a profissão e sua prática profissional, ou seja, o espaço de trabalho que é sua reserva de mercado na sociedade" (MUELLER, 2004, p. 29).

Prosseguindo nessa linha de entendimento da rede de relações e de disputas, Mueller (2004, p. 29) coloca que "A resistência ou fragilidade desses laços são conseqüência da prática diária do trabalho profissional", o que significa que sua permanência dependerá profundamente de suas práticas e do quanto a sociedade perceber da importância delas para satisfação de suas próprias necessidades.

Ao pensar nas profissões "[...] como um sistema ecológico [...]" (MUELLER, 2004, p. 29) no qual as ações de cada segmento interferem no todo, parece ficar mais clara a 
relevância do aspecto relacionado à formação profissional, num sentido amplo, não apenas para os bibliotecários, objeto do presente estudo, mas para qualquer perfil que deseje sobreviver nessa disputa.

Conforme estudos nessa área, Freidson (1998) explica que qualquer tentativa de definição concisa e genérica de profissão esbarra em dificuldades históricas, relações de poder, relações de troca, status e reconhecimento sociais. Freidson (1998, p. 48) disse que:

Sustentarei que a natureza do conceito de profissão nos proporciona um número limitado de opções. A opção que pode levar a um método coerente e sistemático de análise exige que se abandone a tentativa de tratar profissão como um conceito genérico e se volte, em vez disso, para um conceito genérico de ocupação dentro do qual possamos localizar, analiticamente, as ocupações particulares que têm sido rotuladas de profissões. Avançar numa teoria das profissões exige, porém, uma opção um pouco diferente, que trate o conceito como uma construção histórica numa quantidade limitada de sociedades, e estude seu desenvolvimento, uso e conseqüências nessas sociedades sem tentar mais do que a mais modesta das generalizações.

Para estudar uma determinada ocupação considerando-a uma profissão, Freidson (1998, p. 61) coloca que

$\mathrm{Na}$ escolha de ocupações individuais para estudo, portanto, o reconhecimento frouxo como profissão por parte do público em geral, e mesmo a própria pretensão da ocupação - desde que seja levada a sério por algum público importante - podem ser utilizados para localizar casos. Assim, não só médicos, advogados e professores, aceitos tradicionalmente, mas também engenheiros, farmacêuticos, assistentes sociais, professores secundários, bibliotecários e muitos mais a quem o título é atribuído por algum público, mas não por outros, todos podem ser casos adequados à análise, independentemente da maneira como poderiam sob outros aspectos diferir de diversas definições, ou deixar de ajustar-se a elas.

Freidson (1998, p. 246-247) considera que profissão é sinônimo de ocupação e “[...] diz respeito ao trabalho especializado pelo qual uma pessoa ganha a vida numa economia de troca.", "[...] requer conhecimento teórico, competência e discernimento que as pessoas comuns não possuem [...]", que os profissionais realizam um trabalho considerado importante para a sociedade e cujo exercício demanda um período de treinamento para aprender a fazer o trabalho.

Se por profissão entende-se, então, ser a atuação de pessoas que "[...] se dedicam a um conjunto de tarefas profissionais [...]" (MUELLER, 2004, p. 29) é relevante a dedicação ao estudo dessas tarefas e de como ensiná-las para que possam ser exercidas com competência, de modo que os profissionais possam se aparelhar para competir nesse ambiente. Além disso, a formação é fundamental para atender tanto aos anseios da sociedade quanto aos do próprio indivíduo que escolheu, por algum motivo, seguir determinada carreira. 


\subsection{Formação profissional do bibliotecário}

Em texto que discute a formação dos bibliotecários na sociedade da informação, Castro e Ribeiro (2004) são bastante ácidos nas críticas aos profissionais, por considerá-los dissociados da realidade e mais preocupados com as técnicas que com os aspectos sociais do exercício do trabalho na área. Baseados em estatísticas que demonstram a exclusão digital no país, paralelamente ao alto número de analfabetos, dados que podem ser verificados em Baptista (2006), cujo propósito foi o de identificar o papel dos profissionais da informação em processos de inclusão digital, criticam os bibliotecários relacionando características e competências que deveriam possuir, considerando fortemente o aspecto das desigualdades socioeconômicas existentes no país. Baptista (2006) mostra, ainda, que, embasada em dados de sua pesquisa de doutorado, em 1998 existiam relativamente poucos bibliotecários dedicados às bibliotecas públicas e escolares, reiterando, de certo modo, as colocações de Castro e Ribeiro (2004).

Embora não se possa negar a razão de suas críticas, os autores analisam o aspecto da formação profissional reforçando o prisma da desigualdade social, o que igualmente pode redundar em distorções. É fato que a responsabilidade social é parte intrínseca da prática profissional bibliotecária. Entretanto, responsabilidade social não pode ser entendida apenas e somente para os excluídos socialmente, mas, igualmente, para os setores que com suas pesquisas, atuação, produção e possibilidade de oferta de produtos, serviços e empregos podem significar a diferença para os excluídos. E isso torna a formação e a responsabilidade social para atendimento desse segmento tão importante e tão estratégica quanto o olhar para os menos favorecidos e ainda mais complexa a identificação do conjunto de competências que o bibliotecário deve possuir.

Rezende (2002) é outra autora que tem um discurso bastante crítico em relação à atuação dos bibliotecários, à sua formação e, também, acerca dessas tentativas de mudança de nomes da profissão visando torná-la mais visível e reconhecida, especialmente no âmbito de empresas e indústrias. Em seu trabalho, especialmente na parte que trata das bibliotecas nesses contextos, denominando-as "[...] castelos de livros [...]" e relatando que esses espaços "[...] desmoronaram [...]" pela sua ineficiência em responder às necessidades "[...] proporcionando às empresas uma visão mais ampla, que lhes possibilitou compreender que elas precisavam de informação, e não necessariamente de livros e acervos", verifica-se de forma mais evidente sua crítica aos profissionais que atuam nesse espaço.

Para Rezende (2002), essa dissociação entre o que as empresas requeriam e o que os bibliotecários propiciavam e a conseqüente redução dessas bibliotecas tem relação com a formação profissional. A autora comenta que a mudança de paradigma de acesso à informação ocorrendo essa migração das bibliotecas tradicionais, custosas do ponto de vista financeiro, de manutenção e de organização, para um mundo de informações em meio virtual, respostas com valor agregado e com menores requerimentos de desenvolvimento de acervos físicos, teve suas conseqüências para os bibliotecários, conforme seu relato:

Ocorreu, em paralelo, um aumento significativo do número de profissionais de outras áreas e especialidades, que passam a atuar dentro das empresas como intermediários nos processos de gestão da informação, devido, principalmente, ao fato de que a formação acadêmica oferecida pelas escolas de biblioteconomia 
ou ciência da informação já não atendia plenamente às necessidades das empresas.

Retroagindo no tempo, dois textos são recuperados, sendo um o de Milanesi (1983) e outro de Polke, Araújo e Cesarino (1974). A distância temporal não diminuiu a relevância das considerações desses trabalhos e suas preocupações são, de certa forma, complementares, pois enquanto a pesquisa de Milanesi descreveu a formação profissional dos bibliotecários, Polke, Araújo e Cesarino centraram seu interesse na relação dessa formação e o mercado de trabalho em Belo Horizonte.

Polke, Araújo e Cesarino (1974) levantaram, então, o perfil do bibliotecário e na pesquisa foram estudadas: as perspectivas, a visão de profissão e a satisfação com os diferentes aspectos do exercício e da carreira. As conclusões são duras especialmente se destacarmos dois trechos - mesmo considerando que na década de 1970 as mulheres ainda não significavam um aporte financeiro de relevância para as famílias e o casamento ainda era um fator importante de satisfação pessoal, demonstrado pelo alto índice de não exercício profissional relacionado ao casamento, $38,1 \%$ dos pesquisados.

No primeiro trecho, assim se manifestaram as autoras (1976, p. 177):

A baixa expectativa salarial leva-nos a acreditar na passividade do bibliotecário em relação ao mercado de trabalho. Essa passividade pode ser explicada pelo fato da profissão ser predominantemente feminina e se desenvolver principalmente em instituições. Inexiste o profissional autônomo.

No outro, que finaliza o trabalho, Polke, Araújo e Cesarino (1974, p. 177) colocaram que:

É de se espantar que a ideologia do bibliotecário esteja ligada a qualidades sociais e pessoais, em detrimento dos conhecimentos teóricos e técnicos. Isto talvez justifique o fato do profissional não se sentir despreparado para $o$ exercício da profíssão.

E a imagem do profissional que fica é a de "ave de vôo curto"...

Milanesi (1983), por sua vez, teve por interesse em sua pesquisa a formação profissional e a adequação dessa formação à realidade do mercado nacional. Se buscarmos os textos do final do século XX, início do século XXI e as pesquisas que são feitas nessa área, observar-se-á que não há diferenças significativas com relação à adequação dos currículos à realidade, das preocupações com o perfil profissional e a colocação dos bibliotecários relacionados ao mercado e, também, como as Escolas de Biblioteconomia se colocam frente a essas questões. Não está implícita nesse comentário, nenhuma crítica às pesquisas realizadas a partir desse final de século XX, início de século XXI, pois essa revisão da, como disse Milanesi, "fôrma", é importante e sempre atual, pois a sociedade se modifica, as necessidades se alteram, as tecnologias evoluem e a formação profissional de qualquer categoria deve estar sensível a esses pontos. $\mathrm{O}$ que parece não ter mudado é a baixa visibilidade dos bibliotecários pela sociedade, que ainda permeia os textos que tratam desse assunto.

Outros autores revelam preocupações semelhantes com a formação profissional dos 
bibliotecários, como Basefsky (1999) e Souza (2001). O texto de Basefsky (1999) é preciso em suas observações sobre o exercício profissional dos bibliotecários, muito arraigado aos "[..] fazeres tradicionais [...]". Para ele, quando não havia a Internet os bibliotecários não sentiam a concorrência e não se habilitaram a competir no mercado. Assim, considera, Basefsky (1999, p. 37-38, tradução nossa),

[...] a força inerente da profissão bibliotecária é encontrada na sua compreensão do valor da informação. A habilidade de selecionar, a melhor, mais útil informação e organizá-la em categorias para acesso fácil indica que as bibliotecas possuem uma compreensão detalhada do que os clientes necessitam. Infelizmente, o papel tradicional das bibliotecas parou na coleta, organização e assistência e não incluiu, sob nenhuma forma significativa:

- Informar o cliente acerca do material que está sendo coletado presumivelmente a seu pedido. Discutir os temas para os quais o material proveria fundamentação e ilustração;

- Solicitar aos usuários, por intermédio de extensivos programas de demonstração, como utilizar a melhor informação coletada e para qual propósito;

- Selecionar indivíduos chaves para serviços especiais de modo que eles possam transmitir o valor da informação para outros;

- Associar-se com a gerência da instituição na discussão de problemas, projetos, iniciativas de pesquisa e instrução como participante (de política e de decisão) que traz a perspectiva significante do provedor de conhecimento e informação (o bibliotecário) à mesa; ou

- Ampliar a descrição do trabalho bibliotecário ou o papel organizacional da biblioteca para se ajustar melhor às necessidades de informação da organização a que serve.

Para Basefsky (1999, p. 38, tradução nossa) a facilidade relativa de localização de informação na Internet, teve como conseqüência paralela um questionamento, pelos dirigentes, acerca da importância de manter bibliotecas e bibliotecários que significam maior custo para a organização, sem ser evidente o retorno que trazem. Conforme o autor, “[...] se você não é parte da solução, então você é parte do problema." Ele complementa seu pensamento afirmando que: "A maioria das bibliotecas terá que demonstrar sua utilidade para uma organização que não mais entende seu papel e sua função. Nesse processo, o papel e a função do bibliotecário não mudarão muito. $\mathrm{O}$ que mudará será a cultura da Biblioteconomia."

Souza (2001), em texto sobre a função de âncora das escolas de Biblioteconomia no Brasil, também manifesta suas preocupações com o papel dessas escolas, mostrando que em sua história, o eixo da visão de seu corpo docente se concentra em discussões que pouco contribuem para a consolidação da profissão no país. Propostas de mudanças de denominação, por exemplo, conforme o autor, ao invés de consolidar o perfil profissional, não no sentido de manter modos tradicionais de fazer, deveriam incorporar as mudanças à formação e à denominação especial dos bibliotecários, a exemplo do que a medicina e o direito já fazem. Outra crítica do autor é acerca do baixo número de periódicos de divulgação dos desenvolvimentos da área, além de as escolas que formam bibliotecários generalistas: 
Por falta de uma visão clara que articule à profissão os múltiplos papéis que o bibliotecário pode exercer na sociedade, o discurso da Escola visa formar um bibliotecário, na maioria das vezes, para uma biblioteca universal abstrata. Isso faz com que, tanto o aluno quanto o egresso fiquem perdidos em relação a que discurso identitário defender e com qual imagem se apresentar.

\section{EMPREGO E TRABALHO}

Os pontos abordados anteriormente são itens sensíveis no que tange à discussão da formação profissional, da relação dos bibliotecários com seu trabalho e com sua empregabilidade, reconhecida por muitos autores que estudam também as competências dos bibliotecários frente às novas tecnologias e às novas exigências nesse processo. (CABRERA-MORALES, 2004; DUTRA e CARVALHO, 2006; MÁRDERO ARELLANO e ANDRADE, 2006; MILLS, 2006; SANTOS e TOLFO, 2006).

Decorre desses pontos a relevância de esclarecer o que seja emprego, o que se entende por trabalho e do sentido de trabalho para os indivíduos. Embora recorrentemente perceba-se que as pessoas não se preocupam com essa conceituação, ela não deve ser desconsiderada, pois implica em uma visão de mundo que de alguma forma se refletirá no exercício profissional e para a categoria. Essa concepção de trabalho é importante quando pensamos no quanto as tecnologias de informação e de comunicação revolucionaram as relações de emprego e renda, as possibilidades de atuação profissional, as exigências mercadológicas e as fragilidades das relações trabalhistas entre empregados e empregadores.

Em seu artigo sobre os sentidos do trabalho, Morin (2001, p. 10) se reporta ao modelo proposto por Hackman e Oldham (1976) e considera que "[...] um trabalho tem sentido para uma pessoa quando ela o acha importante, útil e legítimo." E, ainda em relação ao modelo, entre as características que contribuem para dar sentido ao trabalho destacamse, segundo Hackman e Oldham (1976, p. 257) ${ }^{1}$ :

1. A variedade das tarefas: a capacidade de um trabalho requerer uma variedade de tarefas que exijam uma variedade de competências.

2 A identidade do trabalho: a capacidade de um trabalho permitir a realização de algo do começo ao fim, com um resultado tangível, identificável.

3. O significado do trabalho: a capacidade de um trabalho ter um impacto significativo sobre o trabalho de outras pessoas, seja na sua organização, seja no ambiente social.

Além desses três itens destacados por Morin (2001), Hackman e Oldham (1976, p. 256) identificam três grandes grupos de características do trabalho e de motivação profissional, conforme colocados por eles na Figura 1, adaptada e abaixo apresentada. Um aspecto importante do artigo é o de que sua proposta era medir os fatores que potencialmente interferem na motivação profissional. E motivação no trabalho pode ser um dos fatores que interferem na construção da imagem profissional dos bibliotecários.

1 Optou-se por utilizar a tradução feita no artigo de Morin (2001, p. 10). 


\begin{tabular}{|c|c|c|}
\hline $\begin{array}{c}\text { Núcleo das } \\
\text { dimensás do } \\
\text { trabalho }\end{array}$ & $\begin{array}{c}\text { Estados } \\
\text { psicologicos } \\
\text { criticos }\end{array}$ & \begin{tabular}{|c|} 
Resultados \\
pessoais o \\
profissionais
\end{tabular} \\
\cline { 3 - 4 }
\end{tabular}

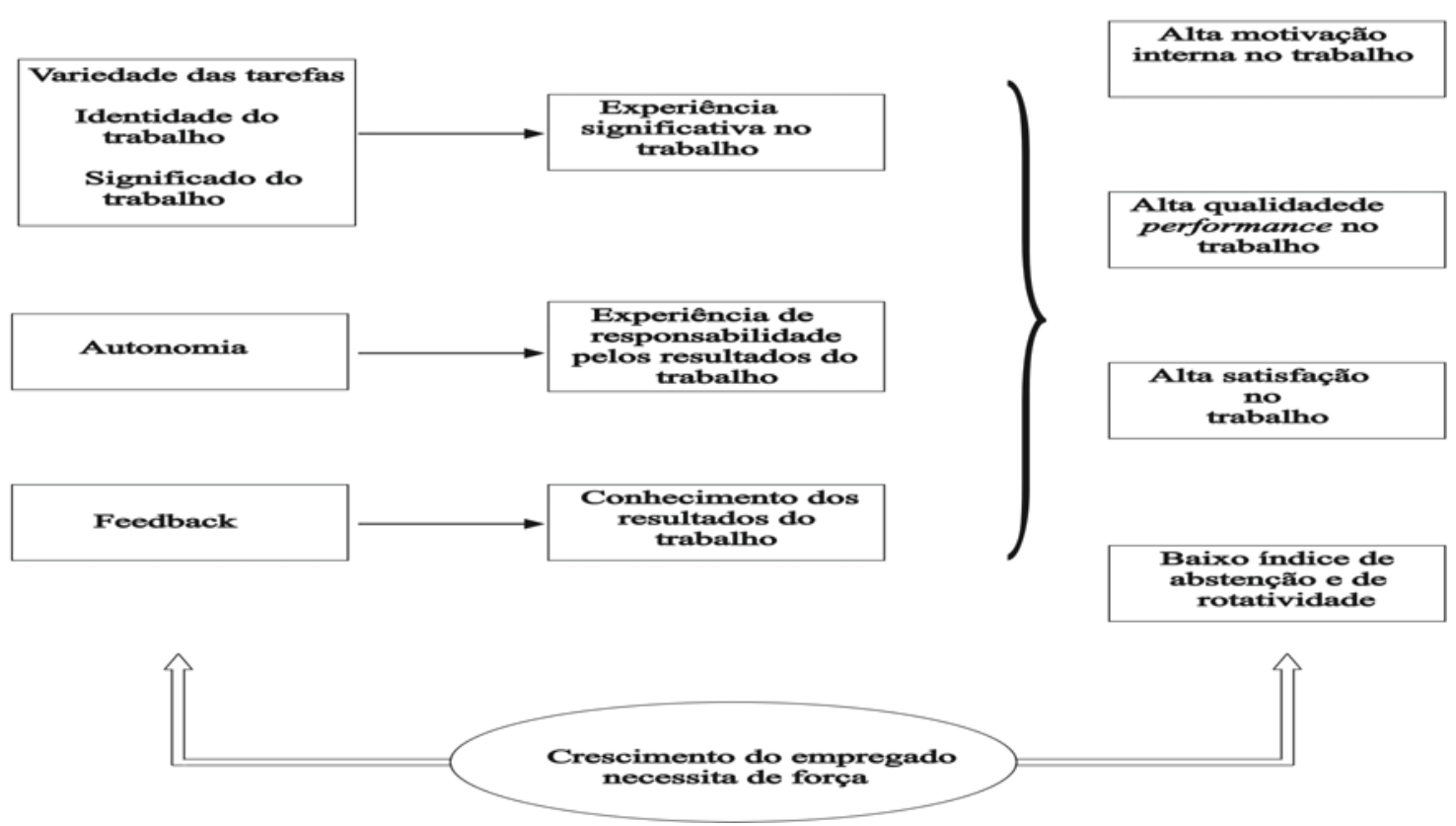

Figura 1 - Características do Trabalho e Motivação Profissional

Fonte: HACKMAN, J. Richard; OLDHAM. Greg R. Motivation through the design of work: test of a theory. Organizational Behavior and Human Performance, v. 16, n. 2, p. 256, Aug. 1976. (adaptação e tradução nossa)

Considerando-se as constantes críticas que são feitas ao trabalho dos bibliotecários, da figura de Hackman e Oldam (1976) destacam-se alguns aspectos que podem servir de alerta tanto a profissionais - bibliotecários - que estão na posição de empregadores quanto na de empregados. Pela coluna do "Núcleo das dimensões do trabalho", por exemplo, coloca-se que a variedade das tarefas, a identidade do trabalho e o significado dele resultam, conforme a coluna relacionada com os "Resultados pessoais e profissionais", em alta motivação interna no trabalho. Paralelamente, analisando-se uma das críticas feitas à profissão de que é rotineira, se é desconsiderada a coluna central "Estados psicológicos críticos", pode-se redundar em profissionais desmotivados para o trabalho, o que causará impactos em efeito cascata para os usuários, para os colegas e para a profissão, que terão sua imagem comprometida por esse baixo nível de motivação profissional.

E, compreender a dimensão do trabalho na vida das pessoas tem relação, evidentemente, com o aspecto da sobrevivência, pois sem trabalho não há sustento e sem o devido provimento de recursos financeiros, nem mesmo em ambientes de agricultura de subsistência as pessoas têm condições minimamente dignas de viver. O que se ressalta, no caso, é que em decorrência desse aspecto absolutamente relevante do significado do trabalho para as pessoas, as organizações empregadoras, e, sobretudo, aquelas 
formadoras de mão-de-obra, deveriam ter consciência desses pontos, relacionando o exercício profissional a essas questões de modo a incorporar, em suas disciplinas, esse procedimento de conscientização para os futuros trabalhadores, que incluem aí os bibliotecários.

Daí a relevância do tema no artigo de Morin (2001), quando a autora, na tentativa de compreender o que é o trabalho chega a uma distinção relacionada ao entendimento do que seja emprego. Para Morin (2001, p. 12) "O trabalho pode ser agradável ou desagradável; ele pode ser associado ou não a trocas de natureza econômica. Ele pode ser executado ou não dentro de um emprego." Já o emprego é definido pela autora como se tratando

[...] da ocupação de uma pessoa, correspondendo ao conjunto de atividades remuneradas em um sistema organizado economicamente. A noção de emprego implica quase necessariamente a noção de salário e do consentimento do indivíduo em permitir que uma outra pessoa dite suas condições de trabalho.

De todo modo, para competir no mercado, seja com a visão e a noção clara do que significa e que sentido tem o trabalho para a categoria profissional ou para se manter "empregável", exige-se que o trabalhador demonstre competência, que se constitui em outro constructo importante no processo de sua formação.

\section{COMPETÊNCIA PROFISSIONAL}

Competência, conforme Brandão (1999, p. 22) dizia respeito, na Idade Média, à faculdade de alguém ou de uma instituição para julgar certas questões. Estudando a evolução do termo, Brandão mostra que competência, no meio empresarial, fícou associada à capacidade de um indivíduo de realizar um determinado tipo de trabalho. Neste capítulo de sua dissertação, o estudo acerca desse constructo é bem profundo e abrangente e remonta a outros autores, como por exemplo, Durand (2000a) ${ }^{2}$, do qual retira os fundamentos da definição adotada por ele.

Durand (2000a) entende ser a competência um conceito baseado em três dimensões que são os conhecimentos, as habilidades e as atitudes, que Brandão sintetizou da seguinte forma:

[...] englobando aspectos cognitivos, técnicos, sociais e afetivos relacionados ao trabalho. Neste caso, competência diz respeito ao conjunto de conhecimentos, habilidades e atitudes interdependentes e necessárias à consecução de determinado propósito.

Durand (2000a) também faz uma extensa revisão dos estudos acerca da evolução do conceito de competência, que encontra suas origens nos trabalhos sobre gerência estratégica. De acordo com ele, no processo de construção de uma teoria sobre esse tema, três abordagens se sucederam que são: "[...] a original, baseada no recurso; depois sua extensão natural, fundamentada sobre o conhecimento e, finalmente, a teoria, ainda emergente, dita da competência [...]."

2 A dissertação de Brandão referencia o trabalho de Durand ainda no prelo, motivo da diferença das datas. 
Adiante, neste artigo, Durand (2000a, p. 95) identifica, então, o que ele denominou de dimensões genéricas da competência e, para exemplificar esta concepção, o autor esquematizou, numa figura bem ilustrativa, os elementos que estão embutidos nessas dimensões.

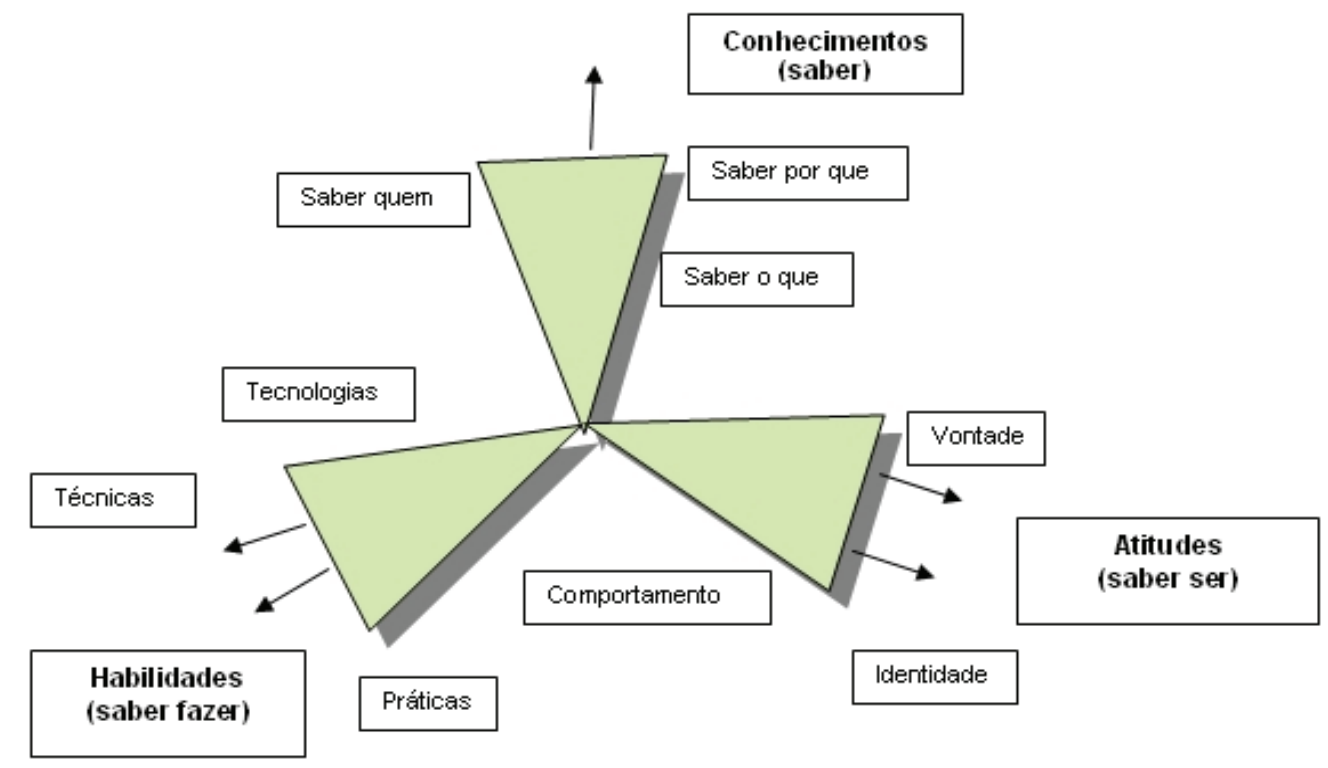

Figura 2 - Três Dimensões da Competência

Fonte: DURAND, Thomas. L'Alchimie de la compétence. Revue Française de Gestion, n.127, p.84102, janv./febr. 2000a. (Adaptação e tradução nossa, da Figura 7)

Analisando-se a questão da competência com base na figura de Durand e traçando-se um paralelo com as práticas profissionais da Biblioteconomia verifica-se o quanto é relevante considerar esses aspectos no processo de formação dos futuros bibliotecários.

Num mundo competitivo e globalizado, conhecimentos (saber) são exigidos não apenas do ponto de vista formal, como normalmente se associa ao conceito, mas, conforme bem ilustra Durand (2000a), saber por que, saber o que se faz e quem faz. Não é difícil, ao questionar profissionais sobre as razões da adoção desta ou daquela opção encontrar respostas como: sempre foi assim. Dessa manifestação depreende-se que as pessoas sabem, do ponto de vista formal, mas desconhecem as razões, o contexto e os cenários, realizando de forma mecânica conhecimentos adquiridos no processo de formação.

Essas questões levam ao segundo ponto identificado por Durand em sua figura que tem relação com a atitude, que por sua vez é associada à vontade, ao comportamento e à identidade. Traçando um paralelo com os bibliotecários, não é incomum a associação desses profissionais a comportamentos como, por exemplo, o de acomodação, que igualmente tem conseqüências para os próprios profissionais e para a profissão. Atitude é um composto fundamental na questão da competência, especialmente se considerado em relação a profissões com baixo reconhecimento social. E pode ser aprendido no processo de formação profissional se o corpo docente se colocar o desafio de desenvolver esse ponto, um passo além do ensino dos conhecimentos e da apreensão 
das habilidades pelos alunos. Esse segmento da competência é sensível, pois se trata de um problema comportamental, que é sem dúvida um desafio, especialmente se consideradas todas as variáveis intervenientes nesse processo que incluem a cultura do professor e dos alunos, o ambiente universitário e social que ambos se inserem, as proposições que cada grupo - docentes e discentes - se colocam num nível mais profundo e interior.

Finalmente, a dimensão relacionada com as habilidades igualmente afeta os bibliotecários no sentido de que suas práticas, técnicas e tecnologias são essenciais para o desempenho profissional. Numa área em que as tecnologias de informação e comunicação revolucionaram de forma profunda os fazeres bibliotecários, ainda se observa que em algumas atividades, como, por exemplo, o de análise de informação, o trabalho continua sendo efetuado, em muitos casos e a despeito de todas as possibilidades existentes nas redes e nos bancos de dados locais e remotos, de forma muito semelhante ao que se fazia quando o suporte para registro e recuperação de informação eram as famosas fichas $12,5 \times 7,5 \mathrm{~cm}$. Pela análise dos bancos de dados das bibliotecas, disponíveis na Internet, é comum perceber que foi feita uma transposição da forma de tratar os documentos nas fichas para as planilhas eletrônicas, sem, entretanto, efetivamente incorporar a relação daquela informação com outras, agregando valor ao trabalho de análise.

Esse relacionamento e integração entre as diferentes fontes e uma noção de que a profissão deve ter suas atividades vistas e executadas de forma integrada e que permitiria que os profissionais ampliassem sua visão do próprio trabalho, também poderiam ou deveriam se constituir em preocupação explícita e evidente do corpo docente na formação profissional para a aquisição de competências.

Voltando a Brandão (1999), é importante sua abordagem pela extensão que alcança no processo de compreensão do tema, especialmente quando introduz a idéia de temporalidade da competência. Baseado em Sparrow e Bonagno (1994), Brandão (1999, p. 30, adaptação nossa) aponta que as competências podem ser consideradas:

- Emergentes, [...] como exemplo, capacidade de navegar na Internet [...];

- Declinantes, [...] como a capacidade de datilografar $[\ldots]$;

- Estáveis ou essenciais, [...] raciocínio lógico $[\ldots]^{3}$;

- Transitórias, competências que embora essenciais em momentos críticos de transição não estão diretamente relacionadas com o negócio da organização, [...] como a capacidade de administrar o stress e trabalhar sob pressão.

O trabalho de Sparrow e Bonagno (1994) analisa a importância da gestão de recursos humanos pelas competências; explica que existe uma distinção entre competence (conceito utilizado no Reino Unido) e competencies (abordagem advinda de organizações que identificam as próprias competências); apresenta a experiência da British Petroleum na utilização da gestão baseada em competências como um modo de facilitar a estratégia de mudanças; e, conforme apropriadamente extraiu Brandão (1999),

3 No texto de Sparrow e Bonagno (1994, p. 66) essas competências são definidas como aquelas que permanecerão importantes no futuro como são no presente e que estão no núcleo da efetividade da performance. 
identifica um ciclo de vida das competências organizacionais, traduzida, então, nessas quatro definições: emergentes, declinantes, estáveis ou essenciais e transitórias.

Mesmo considerando que o foco de Sparrow e Bonagno (1994) tenha sido nas competências organizacionais, considerando-se o fator humano das organizações, a Figura 3, abaixo, pode ser um interessante paradigma para os profissionais pensarem sobre suas próprias competências numa linha do tempo:

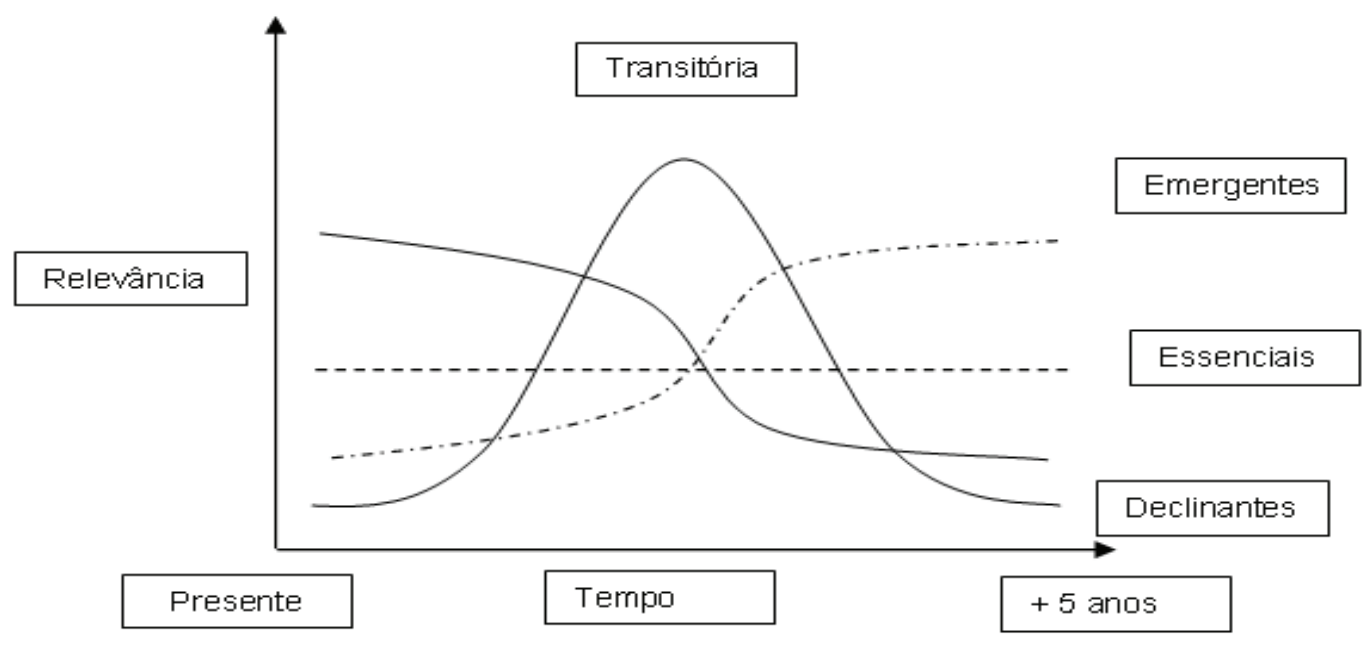

Figura 3 - Ciclo de Vida de Competências Organizacionais

Fonte: SPARROW, Paul R.; BONAGNO, Mario. Competency requirement forecasting: issues for international selection and assessment. In: MABEY, Christopher; ILES, Paul (Ed.). Managing learning. London: Routledge, 1993. p. 66. (Tradução nossa da Figura 5.1)

O que é relevante dessa colocação é exatamente o grau de importância que o aprendizado contínuo e a análise constante da carreira e dos desenvolvimentos técnicos ou tecnológicos representam na vida profissional dos indivíduos. Na universidade os futuros bibliotecários adquirem algumas competências que se revelam transitórias no trabalho, independentemente da atividade que desempenham, utilizam outras que são essenciais, assim como percebem outras que podem ser emergentes ou declinantes. Em relação, sobretudo, às competências que têm essas características mais marcantes de serem emergentes ou declinantes, conforme a passagem do tempo, evidencia-se o componente de necessidade de aprendizado contínuo que possibilitará, então, aos profissionais, voltando a Morin (2003, p. 16), "[...] navegar em um oceano de incertezas em meio a arquipélagos de certezas."

Esses aspectos são também apontados por Passos e Santos (2005, p. 14) quando dizem que "[...] o mercado atual exige mais que uma formação profissional, acrescida de especializações, pós-graduações, cursos, isto é propriamente a educação permanente, que exige de cada indivíduo uma constante busca de sua estabilidade profissional.”

Aliado a esses fatores inclui-se ainda, nesse cenário, a discussão sobre os profissionais da informação e suas competências, que possuem vários pontos que convergem para o que se discute, em muitos casos, acerca da formação profissional dos bibliotecários. 


\subsection{Competências do Moderno Profissional da Informação}

Em artigo que trata da formação do profissional da informação para o século XXI, Abels et al. (2003, tradução nossa) iniciam seu artigo definindo o que entendem por profissional da informação que, segundo eles, é aquele que:

[...] estrategicamente utiliza informação em seu trabalho de forma a contribuir para que a organização cumpra sua missão. O profissional da informação realiza isso por meio do desenvolvimento, implementação e gerência de recursos e serviços de informação.

Os autores prosseguem em sua definição de profissional da informação dizendo que este utiliza a tecnologia como uma ferramenta crítica para atingir seus objetivos e inclui bibliotecários, gerentes de conhecimento, gerentes, pessoas que desenvolvem páginas web, intermediários da informação e consultores, dentre outros.

Segundo Abels et al. (2003, tradução nossa) para o exercício de suas atividades esses profissionais da informação requerem dois tipos de competência que são as profissionais e a pessoais.

Entre as competências profissionais são listadas:

- Gerência de organizações de informação;

- Gerência de recursos de informação;

- Gerência de serviços de informação;

- Utilização de ferramentas e tecnologias de informação.

As competências pessoais, conforme os autores,

[...] representam um conjunto de atitudes, habilidades e valores que os habilitam a trabalhar efetivamente e contribuir positivamente para as suas organizações, seus clientes e para a profissão. Entre essas competências incluem-se desde ser comunicadores, saber demonstrar o valor agregado de suas contribuições, ser flexíveis e positivos em ambientes em constante mudança.

Abels et al. (2003, tradução nossa) consideram que esses dois grupos de competências formam o que denominaram de núcleo de competências essenciais e que podem ser sintetizados em:

I - Profissionais da informação contribuem para a base do conhecimento da profissão pelo compartilhamento das melhores práticas e experiências e continuam a aprender sobre produtos, serviços e práticas de gerenciamento da informação, ao longo de suas carreiras;

II - Profissionais da informação são comprometidos com a excelência e a ética profissionais e com os valores e princípios da profissão.

Outros autores tratam igualmente de discutir as competências, as atitudes e os comportamentos desejáveis para os profissionais da informação, como Merlo Vega (2006, tradução nossa), que faz um extenso retrospecto de trabalhos em que se identificam essas competências e relaciona o que ele denominou de decálogo de sugestões sobre como deve ser "[...] um trabalhador da informação que quer contribuir 
para o desenvolvimento da profissão e para o reconhecimento dela" que inclui: estar informados, ser competentes, ser ativos, saber adaptar-se, saber promover-se, sentir-se importante.

Valentim (2002, p. 122-130) é outra autora que sintetiza, em seu texto, os vários itens que compõem essa extensa lista para a qual também os bibliotecários devem estar atentos no exercício profissional. A despeito da variedade e complexidade de itens, entretanto, Valentim (2002, p. 130) considera, então, que:

Pelo exposto, verifica-se a necessidade de repensar a formação do profissional da informação, entender a formação de maneira mais ampla, mais global, buscando um profissional capaz de entender seu mundo. Estabelecer competências e habilidades para o profissional da informação, portanto, não é problema. O problema está na maneira como o profissional entende a sociedade e de que forma ele, o profissional, atende seus anseios.

Mesmo discordando da autora quando ela considera que atingir todos os níveis de exigência do mercado e as demandas sociais, além de desenvolver as competências requeridas para o exercício profissional não poder ser entendido como "problema", pois isso parece ser um excesso de simplificação e otimismo num mundo tão complexo, não se pode deixar de reconhecer sua razão quando busca convergir os pontos relacionados com formação, educação continuada e exercício profissional, como ingredientes que integram o conjunto de fatores relacionados com a formação profissional e o perfil profissional dos bibliotecários, inseridos no grupo ocupacional dos profissionais da informação.

Dentre as diversas listas de recomendações dos autores acerca do grupo de competências que devem ter os modernos profissionais da informação incluem-se, conforme Guimarães (1998): 


\begin{tabular}{|c|c|}
\hline $\begin{array}{ll}\text { - } & \text { Flexibilidade. } \\
\text { - } & \text { Visão gerencial. } \\
\text { - } & \text { Capacidade de análise. } \\
\text { - } & \text { Criatividade. } \\
\text { - } & \text { Liderança. } \\
\text { - } & \text { Dinamismo. } \\
\text { - } & \text { Responsabilidade. } \\
\text { - } & \text { Visão interdisciplinar. } \\
\text { - } & \text { Atuação interdisciplinar. } \\
\text { - } & \text { Profissionalismo. } \\
\text { - Ética. } \\
\text { - } \\
\text { Conhecimentos sobre } \\
\text { organização do } \\
\text { conhecimento. } \\
\text { - Visão política na área de } \\
\text { informação. } \\
\text { Uso da informação para } \\
\text { vantagem competitiva. } \\
\text { Uso da informação para o } \\
\text { desenvolvimento social e } \\
\text { humano }\end{array}$ & $\begin{array}{ll}\text { - } & \text { Treinamento em recursos } \\
\text { informacionais. } \\
\text { - } & \text { Espírito investigativo. } \\
\text { - } & \text { Ação investigativa. } \\
\text { - } & \text { Compromisso com a abertura } \\
\text { de novos mercados de } & \text { trabalho } \\
\text { - } & \text { Objetividade e crítica: clareza, } \\
\text { precisão e concisão. } \\
\text { - } \begin{array}{l}\text { Agilidade mental. } \\
\text { - }\end{array} \text { Motivação interna para } \\
\text { desfrutar do trabalho como } \\
\text { recompensa pessoal } \\
\text { - Habilidade para a solução de } \\
\text { problemas. } \\
\text { Coragem para enfrentar os } \\
\text { riscos, pois sua iminência é } \\
\text { cada vez maior em tempos de } \\
\text { competitividade. }\end{array}$ \\
\hline
\end{tabular}

É evidente que esse conjunto é necessário e desejável no processo de formação dos bibliotecários, que são inegavelmente profissionais da informação, mesmo quando não são considerados modernos. E é igualmente relevante verificar em que medida os cursos estão preparados e preparando os alunos para terem esse perfil, especialmente considerando-se que a denominação do bibliotecário parece ser considerada fator limitante, embora esse ponto não esteja em discussão no presente trabalho, mas deve ser considerado, como bem frisa Souza (2006), que critica essa tendência nos cursos e inclui entre os problemas para que o bibliotecário seja reconhecido socialmente, construa sua identidade e se afirme em suas competências.

\section{CONCLUSÃO}

Uma formação profissional conectada com as mudanças originadas pela introdução de ferramentas tecnológicas para o armazenamento e recuperação da informação e a educação continuada são condições necessárias para o bibliotecário sobreviver no espaço competitivo que existe no mundo do trabalho. Além do advento das novas tecnologias, a empregabilidade é influenciada por outros paradigmas como a fragilidade do emprego, que emerge de forma mais evidenciada com a globalização, a competitividade e outros fatores atrelados a uma exigência cada vez maior por especialização, para quem quer se inserir no mercado. Nesse sentido, empregabilidade envolve discussões que perpassam outras questões como as competências, a qualificação ou a escolaridade.

Daí, o papel da escola é questionado, pois deve buscar manter os currículos em consonância com as exigências mercadológicas, mas atenta às necessidades sociais, assim como são importantes as iniciativas do profissional em busca da educação continuada. 
Na prática, percebe-se, por alguns estudos de mercado de trabalho do bibliotecário, que os profissionais são acomodados e fazem poucos investimentos em educação continuada, conforme Baptista (1998) e Baptista et al. (2007). Entretanto, se, de alguma forma, os Conselhos de Biblioteconomia continuam aparentemente "protegendo" a classe, pois garantem o mercado das bibliotecas, por outro lado não atuam no sentido de ampliar a visão da profissão pela e para a sociedade, apontando outros tipos de sistemas de informação, onde o bibliotecário poderia atuar.

A literatura sobre o assunto "exigências do mercado" repete, incessantemente, que existe uma mudança e que essa mudança requer mais do que as competências básicas no tratamento e recuperação da informação. A procura pelos cursos de mestrado e doutorado em Ciência da Informação do país tem mostrado que profissionais com outras formações têm buscado essa competência e certamente vão completar essa formação básica, adquirida nos cursos de graduação, com as suas capacidades administrativas e tecnológicas para atuarem em qualquer sistema de informação, competindo fortemente com os bibliotecários. Estes por sua vez, aparentemente relutam em prosseguir nos estudos, diminuindo, de certa forma, suas possibilidades de acesso a mercados diferenciados e, talvez, mais vantajosos, do ponto de vista das perspectivas profissionais e da remuneração.

Entende-se que o somatório das competências adquiridas com a prática diária e com investimentos na formação profissional continuada proporcionará, ao profissional, melhores condições para atuar no mercado da informação, ancorado em sólido embasamento teórico e prático.

\section{REFERÊNCIAS}

ABELS, Eileen et al. Competencies for information professionals of the $\mathbf{2 1}^{\text {th }}$ century. Disponível em: $<$ http://www.sla.org/content/SLA/professional/meaning/comp2003.clin $>$. Acesso em: 11/08/2003. Revised edition, June 2003.

BAPTISTA, Sofia Galvão; Passos, Edilenice J. Lima ; SOARES, M. G.; SOUSA, L. A. G. Características do perfil do bibliotecário que atua na área jurídica no Distrito Federal. In: Seminário Nacional de Documentação e Informação Jurídica, 2007, Brasília. Anais do Seminário Nacional de Documentação e Informação Jurídica. Brasília: Senado Federal, 2007. p. 1-28.

A inclusão digital: programas governamentais e o profissional da

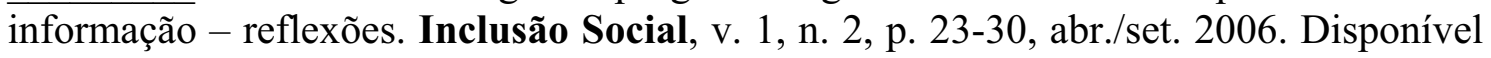
em: < http://www.ibict.br/revistainclusaosocial/search.php?op=authorDetail\&id=40>. Acesso em: 3/06/2006.

Bibliotecário autônomo versus institucionalizado: carreira, mercado de trabalho e comprometimento organizacional. 1998. 234 f. Tese (Doutor) - Curso de Doutorado em Ciência da Informação, Departamento de Ciência de Informação e Documentação, Universidade de Brasília, Brasília, 1998.

BASEFSKY, Stuart. The library as na agent of change: pushing the client institution foreward. Information Outlook, v. 3, n. 8, p. 37-40, Aug. 1999. 
BRANDÃO, Hugo Pena. Gestão baseada nas competências: um estudo sobre competências profissionais na indústria bancária. 1999.158 f. Dissertação (Mestrado em Administração Universidade de Brasília, Departamento de Administração, Brasília, 1999).

CABRERA-MORALES, Idalmis M. Comportamiento de las nuevas tecnologías de la información y su impacto en el trabajo bibliotecário. In: FORO SOCIAL DE INFORMACIÓN, DOCUMENTACIÓN Y BIBLIOTECAS, 2004, Buenos Aires. Programas de acción alternativa desde Latinoamérica para la sociedad del conocimiento. Disponível em: $<$ http://www.inforosocial.org/ponencias/eje03/15.pdf $>$. Acesso em: 20/01/2005.

CASTRO, César Augusto; RIBEIRO, Maria Solange Pereira. As contradições da sociedade da informação e a formação do bibliotecário. Revista Digital de Biblioteconomia e Ciência da Informação, v. 1, n. 2, p. 41-52, jan./jun. 2004.

DURAND, Thomas. Forms of incompetence. Advances in Applied Business Strategy, v. 6A, p. 69-95, 2000.

DURAND, Thomas. L'Alchimie de la compétence. Revue Française de Gestión, n. 127, p. 84-102, janv./febr. 2000a.

DUTRA, Tatiana N. Augusto; CARVALHO, Andréa Vasconcelos. O profissional da informação e as habilidades exigidas pelo mercado de trabalho emergente. Encontros Bibli: Revista Eletrônica de Biblioteconomia e Ciência da Informação, n. 22, $2^{\circ}$ sem. 2006. Disponível em: <http://www.encontros-bibli.ufsc.br/Edicao_22/dutra.pdf $>$. Acesso em: 8/04/2007.

FREIDSON, E. O renascimento do profissionalismo: teoria, profecia e política. São Paulo: Edusp, 1998. 280 p.

GUIMARÃES, José Augusto. Moderno profissional da informação: elementos para sua formação e atuação no Mercosul com vistas ao terceiro milênio. In: ENCUENTRO DE DIRECTORES, 3.; ENCUENTRO DE DOCENTES DE LAS ESCUELAS DE BIBLIOTELOGÍA DEL MERCOSUR, 2., Santiago de Chile, 1998. Formación de recursos humanos en el área de la información en el Mercosur: compatibilización curricular; competencias del profesional de la información en el Mercosur. Disponível em: $<$ http://www.utem.cl/deptogestinfo/extension.htm>. Acesso em: 7/09/2007.

HACKMAN, J. Richard; OLDHAM, Greg R. Motivation throuh the design of work: test of a theory. Organizational Behaviour and Human Performance, v. 16, p. 250279, 1976.

MÁRDERO ARELLANO, Miguel Ángel; ANDRADE, Ricardo Sodré. Preservação digital e os profissionais da informação. DataGramaZero - Revista de Ciência da Informação, v. $7, \quad$ n. 5 , out. 2006. Disponível em: $<$ http://www.dgz.org.br/out06/Art_05.htm >. Acesso em: 22/10/2006.

MERLO VEGA, José Antonio. La profesión de arquivos, bibliotecas y centros de documentación: Dónde estamos? Dónde tenemos que estar? Las claves de la visibilidad y algunas ideas para querernos. In: JORNADA ESTRATÉGICA DE REVITALIZACIÓN / ALDEE, 2006, Bilbao. La profesión de arquivos, bibliotecas y centros de documentación. Disponível em: $<$ http://eprints.rclis.org/archive/00007266/>. Acesso em: 6/04/2007.

MILANESI, Luís. Forma/formação/fôrma do bibliotecário. Palavra Chave, São Paulo, n. 3, p. 3-10, 1983. Disponível em: $<$ http://academica.extralibris.info/bibliotecario/forma_formacao_forma_do_biblio.html $>$. Acesso em: 30/10/ 2006. 
MILLS, Elinor. Most reliable search tool could be your librarian. News.Com, atual. Sept. 29 2006. Disponível em: <http://news.com.com/2100-1032_3-6120778.html>. Acesso em: 4/10/2006.

MORIN, Edgar. Prólogo. In: . Os sete saberes necessários à educação do futuro. 8. ed. São Paulo: Cortez; Brasília: Unesco, 2003. p. 13-18.

MORIN, Estelle M. Os sentidos do trabalho. Revista de Administração de Empresas, v. 41, n. 3, p. 8-19, jul./set. 2001.

MUELLER, Suzana Pinheiro Machado. Uma profissão em evolução: profissionais da informação no Brasil sob a ótica de Abbott - proposta de estudo. In: BAPTISTA, Sofia Galvão; MUELlER, Suzana Pinheiro Machado (Org.) Profissional da informação: o espaço de trabalho. Brasília: Thesaurus / CID-UnB, 2004. p. 23-54.

PASSOS, Rosemary; SANTOS, Gildenir Carolino. Formação da identidade profissional do bibliotecário: o desenvolvimento de competência e habilidades na área educacional. In: _ (Org. . Competência em informação na sociedade da aprendizagem. 2. ed. rev. Bauru: Kairós, 2005. p. 9-28.

POLKE, Ana Maria Athayde; ARAÚJO, Elizabeth de Melo Bomfim; CESARINO, Maria Augusta da Nóbrega. Análise do mercado de trabalho do bibliotecário em Belo Horizonte. Revista da Escola de Biblioteconomia da UFMG, v. 5, n. 2, p. 165-177, set. 1976.

REZENDE, Yara. Informação para negócios: os novos agentes do conhecimento e a gestão do capital intelectual. Ciência da Informação, v. 31, n. 2, maio/ago. 2002.

SANTOS, Angela Sirokski; TOLFO, Suzana da Rosa. Competências demandadas dos bibliotecários frente à novas tecnologias de informação em bibliotecas universitárias. Encontros Bibli: Revista Eletrônica de Biblioteconomia e Ciência da Informação, n. 21, $1^{\text {o }}$ sem. 2006. Disponível em: <http://www.encontrosbibli.ufsc.br/Edicao_21/santos.pdf>. Acesso em: 8/04/2007.

SOUZA, Francisco das Chagas de. A escola de Biblioteconomia e a ancoragem da profissão de bibliotecário. Revista Informação \& Sociedade: Estudos, v. 11, n. 2, 2001. Disponível em: <http://www.informacaoesociedade.ufpb.br/issuev.11n.201.html $>$. Acesso em: 22/10/2002.

SOUZA, Francisco das Chagas de. A formação acadêmica de bibliotecários e cientistas da informação e sua visibilidade, identidade e reconhecimento social no Brasil. Informação \& Sociedade: Estudos, João Pessoa, v. 16, n. 1, p. 32-46, jan./jun. 2006.

SPARROW, Paul R.; BONAGNO, Mario. Competency requirement forecasting: issues for international selection and assessment. In: MABEY, Christopher; ILES, Paul (Ed.). Managing learning. London: Routledge, 1993. p. 57-69.

VALENTIM, Marta Lígia Pomim. Formação: competências e habilidades do profissional da informação. In: _ _ (Org.). Formação do profissional da informação. São Paulo: Polis, 2002. p. 117-132.

\footnotetext{
ABSTRACT

Professional education of any professional category comprehends variable aspects including questions on ethics, employment capacity, job, profession and employment concepts. In the librarians case specially, these points are discussed based on literature, inserting questions about what is competence and which ones are highlighted by authors when they list competences that professionals should have to be recognized as modern information professionals. Besides that, the task of elaborating curricula that fill every
} 
determined requirement is very complex. Add to that it is unavoidable to stress questions related to information and communication technologies whose importance in the librarians' work is becoming greater and greater, and their use more intensive and determinant for those that wish to develop information products and services each time more suitable to their clients.

KEYWORDS: Professional education. Librarians. Competence. Profession. Employment. Job.

Originais recebidos em: 27/09/2007

Texto aprovado em: 13/03/2008

Nota: Parte do artigo é extraído de capítulo de tese sob orientação da Professora Doutora Sofia Galvão Baptista, a ser defendido junto à UnB, Departamento de Ciência da Informação e Documentação. 